\title{
The Complex Interplay of Parasites, Their Hosts, and Circadian Clocks
}

\author{
Priscilla Carvalho Cabral ${ }^{1,2}$, Martin Olivier $^{2}$ and Nicolas Cermakian ${ }^{1 *}$ \\ ${ }^{1}$ Laboratory of Molecular Chronobiology, Douglas Mental Health University Institute, McGill University, Montreal, QC, \\ Canada, ${ }^{2}$ Laboratory of Infectious Diseases and Immunity, Department of Medicine, Research Institute of the McGill \\ University Health Center, McGill University, Montreal, QC, Canada
}

\section{OPEN ACCESS}

Edited by:

Marina Maria Bellet,

University of Perugia, Italy

Reviewed by:

Celio Geraldo Freire-de-Lima,

Federal University of Rio de

Janeiro, Brazil

Sarah Reece,

University of Edinburgh,

United Kingdom

*Correspondence:

Nicolas Cermakian

nicolas.cermakian@mcgill.ca

Specialty section:

This article was submitted to

Parasite and Host,

a section of the journal

Frontiers in Cellular and Infection

Microbiology

Received: 11 October 2019 Accepted: 28 November 2019 Published: 12 December 2019

Citation:

Carvalho Cabral P, Olivier M and Cermakian N (2019) The Complex Interplay of Parasites, Their Hosts, and Circadian Clocks.

Front. Cell. Infect. Microbiol. 9:425. doi: 10.3389/fcimb.2019.00425
Parasites have evolved various mechanisms to favor infection of their hosts and enhance the success of the infection. In this respect, time-of-day effects were found during the course of parasitic infections, which can be caused or controlled by circadian rhythms in the physiology of their vertebrate hosts. These include circadian clock-controlled rhythms in metabolism and in immune responses. Conversely, parasites can also modulate their hosts' behavioral and cellular rhythms. Lastly, parasites themselves were in some cases shown to possess their own circadian clock mechanisms, which can influence their capacity to infect their hosts. A better knowledge of the circadian regulation of hostparasite interactions will help in designing new preventive and therapeutic strategies for parasitic diseases.

Keywords: parasite, host, circadian rhythms, circadian clock, infection, immune response, behavior

\section{INTRODUCTION}

Various aspects of physiology and cell function present self-sustained $\sim 24 \mathrm{~h}$ variations termed circadian rhythms. In mammals, a central clock located in the Suprachiasmatic Nucleus (SCN) in the hypothalamus controls daily cycles of rest and activity, body temperature, and hormone levels. The discovery of clock genes, encoding the molecular components of circadian clocks (Duguay and Cermakian, 2009; Takahashi, 2017), opened new doors in chronobiology research in challenging this centralized view of the circadian system. First, the rhythmic expression of these clock genes in almost every cell of the body showed that circadian oscillators are virtually ubiquitous (Takahashi, 2017). Second, mouse models with mutated clock genes allowed to investigate the impacts of clock genetic dysfunction on physiology, and tissue-specific roles of circadian clocks (Duguay and Cermakian, 2009).

Parasitic infections are a major concern worldwide, with millions dying each year and many more living with complications. Curiously, despite an emerging literature about the circadian control of host-microbe interactions, including bacterial and viral infection, very little has been published on the circadian influences on parasitic infections. Various physiological system that could impact parasite life cycles are under circadian control, for example metabolism (Bass, 2012) and immunity (Labrecque and Cermakian, 2015; Nobis et al., 2018). Host physiology could use circadian clocks to anticipate the time of parasite infection and thus optimize its cellular defenses; on the other hand, the parasite itself might have evolved to take advantage of the rhythmicity in the host to enhance its infectivity. This article will first provide an overview of how the host's circadian rhythms can impact parasitic infections. We will then review known circadian rhythms in parasites, as well as parasite-induced changes in the host's circadian rhythms (Figure 1). We refer the readers to recent reviews for discussion of the circadian rhythmicity in insect vectors (MeirelesFilho and Kyriacou, 2013; Rund et al., 2016) and of evolutionary and ecological aspects of daily rhythms in host-parasite interactions (Martinez-Bakker and Helm, 2015; Westwood et al., 2019). 


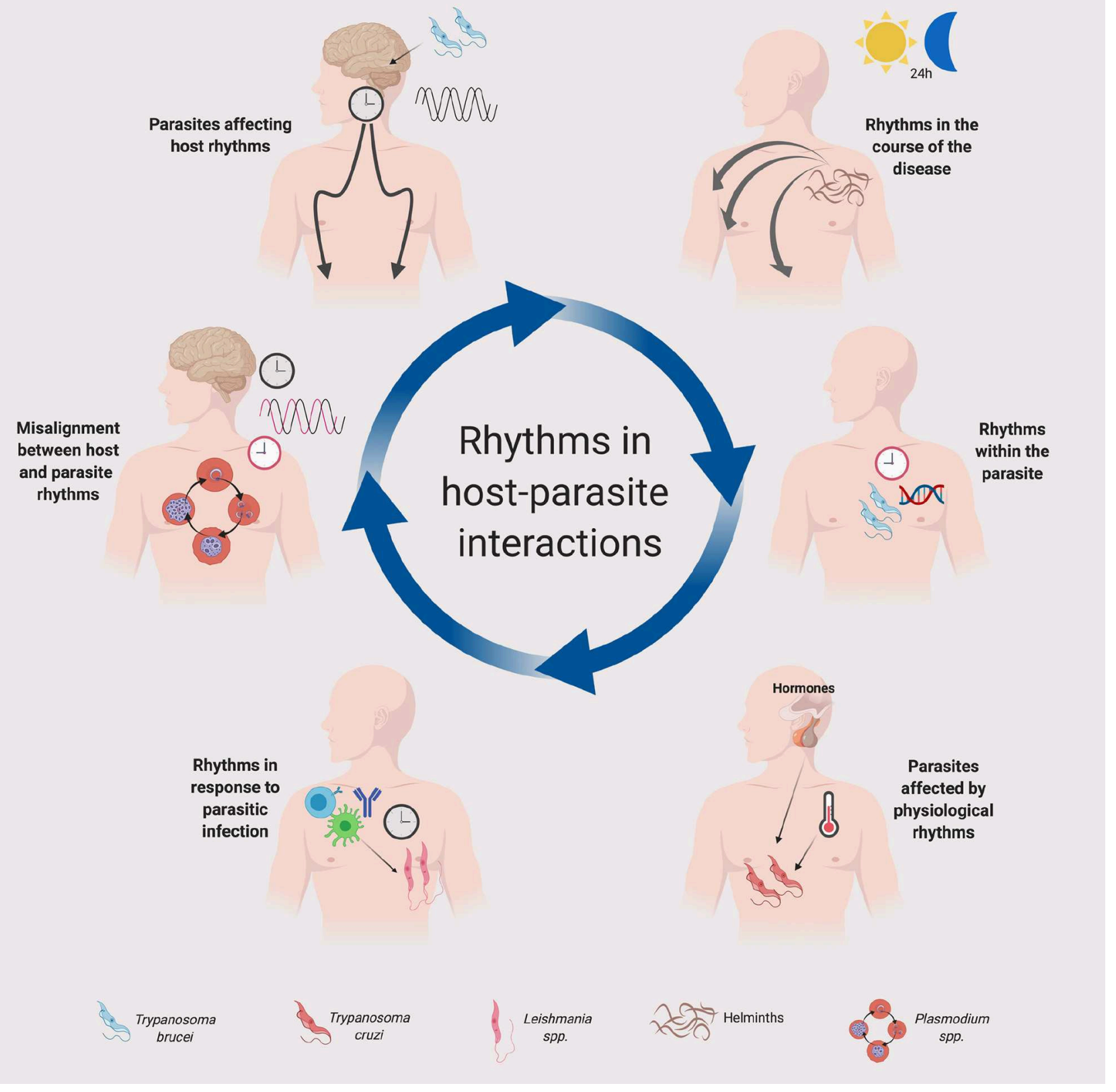

FIGURE 1 | Rhythms in host-parasite interactions. A schematic summary is provided for the implication of daily or circadian rhythms in parasites and their hosts. Host clocks and parasite clocks are depicted in black and red, respectively. The legend at the bottom indicates the parasites represented in the figure. Although in the figure we depicted some specific parasites for illustration purposes, the principles represented in this figure could apply to other parasite groups and species. See text for details. Created with Biorender.com.

\section{RHYTHMS IN THE COURSE OF THE DISEASE}

Clinical and experimental observations have highlighted rhythms in symptoms resulting from parasitic infection (Table 1). For example, patients infected with the malaria parasite Plasmodium spp. show oscillations in fever and chills with periods that are multiples of $24 \mathrm{~h}$ (Hawking et al., 1968; Karunaweera et al., 1992).
This is paralleled by a 24,48 , or $72 \mathrm{~h}$ developmental cycle within red blood cells (RBCs), depending on the parasite species (Reece et al., 2017). Indications of rhythms also exist in leishmaniasis: blood samples collected from patients in the daytime contained fewer Leishmania amastigotes than night time-collected samples (Saran et al., 1997). In the case of urinary schistosomiasis, a rhythm in egg elimination was observed to peak around midday (Doehring et al., 1985). 
TABLE 1 | Circadian rhythms in host-parasite interactions for selected parasites ${ }^{a}$

\begin{tabular}{|c|c|c|c|c|}
\hline Parasite & $\begin{array}{l}\text { Rhythms in } \\
\text { the course } \\
\text { of infection }\end{array}$ & $\begin{array}{l}\text { Effects of host's } \\
\text { immune cells or } \\
\text { mediators }\end{array}$ & $\begin{array}{l}\text { Parasite- } \\
\text { intrinsic } \\
\text { rhythms }\end{array}$ & $\begin{array}{c}\text { Modulation } \\
\text { of host's } \\
\text { rhythms }\end{array}$ \\
\hline $\begin{array}{l}\text { Plasmodium } \\
\text { spp. }\end{array}$ & $\checkmark$ & $\checkmark$ & $\checkmark$ & $\checkmark^{b}$ \\
\hline $\begin{array}{l}\text { Trypanosoma } \\
\text { brucei }\end{array}$ & & & $\checkmark$ & $\checkmark$ \\
\hline $\begin{array}{l}\text { Leishmania } \\
\text { spp. }\end{array}$ & $\checkmark$ & $\checkmark$ & & \\
\hline Helminths ${ }^{c}$ & $\checkmark$ & $\checkmark$ & & $\checkmark^{d}$ \\
\hline $\begin{array}{l}\text { Botrytis } \\
\text { cinerea }\end{array}$ & $\checkmark$ & & $\checkmark$ & \\
\hline
\end{tabular}

${ }^{a}$ Check symbols $(\checkmark)$ indicate cases where experimental observations have been made. Absence of check symbol means that to our knowledge, it has not been investigated. See main text for references.

${ }^{b}$ Likely due to an effect of inflammatory mediators.

'On this line, observations for various parasitic worms are aggregated.

${ }^{d}$ Only observed at the behavioral level; no evidence yet that the effect is on host's clocks.

Daily oscillations of the number of microfilariae, an early stage in nematode blood parasite development, have been widely reported. For instance, high nightly counts of Dirofilaria repens microfilaria were observed in dogs (Di Cesare et al., 2013). A similar pattern was observed with Wuchereria bancrofti (Hawking, 1967), presumably an adaptation to the night-biting Anopheles and Culex insect vectors (Reece et al., 2017). In contrast, the Pacific-type $W$. bancrofti has a greater number of parasites in circulation in the afternoon (Hawking, 1967), consistent with the phase of biting behavior of its diurnal vector, Aedes. Other studies showed that cutaneous abundance of microfilariae in dogs also varied in a manner consistent with the time of peak activity of their vectors (Duke et al., 1967; Otranto et al., 2013). The $24 \mathrm{~h}$ rhythm in parasite load in the blood is a consequence of the microfilaria migration to peripheral tissues (Hawking, 1967).

Hawking proposed that parasites benefit from adapting their time of maximal transmissibility to the time of day the insect vector is foraging, and thus, is most likely to take up the parasites (Hawking, 1967; Reece et al., 2017). This was supported by his work on microfilaria described above. Although Hawking proposed that the same could apply to malaria (Hawking, 1970), definitive proof of this has been lacking. In a recent study, however, partial support for the hypothesis was provided using $P$. chabaudi-infected mice: although fewer gametocytes were in circulation at night, and mosquitos were less likely to be infected, nighttime gametocytes were more infectious, as seen by a higher oocyte burden in mosquitos 8 days after blood meal (Schneider et al., 2018).

\section{PARASITES AFFECTED BY PHYSIOLOGICAL RHYTHMS}

\section{Temperature}

The rhythms observed during the course of parasitic infections might be due to host rhythms, such as the body temperature rhythm. Hawking and colleagues addressed this for both microfilaria and Plasmodium infections. In microfilaria-infected patients and animals, modifying the body temperature cycles affected microfilaria blood counts (Hawking et al., 1967, 1981). In monkeys infected with $P$. knowlesi, and in chick eggs infected with $P$. lophurce, an artificial inversion of the body temperature cycle led to a phase shift of the parasite cycles (Hawking et al., 1968). While interesting, these experiments were often on small numbers of animals or patients, so the effects of temperature on parasite rhythms has remained an open question. In experiments where Plasmodium-infected mice were kept on an inversed feeding regimen, the body temperature rhythm was unchanged but the intra-RBC development cycle was reversed, showing that the former is not synchronizing parasite development in RBCs (Prior et al., 2018). However, Trypanosoma brucei cultured in vitro showed rhythms of gene expression that were entrained by temperature cycles (Rijo-Ferreira et al., 2017).

\section{Melatonin}

Melatonin is a well-known circadian hormone in many vertebrates, and several studies addressed its possible role in regulating parasite rhythms. For example, exogenous melatonin administration suppressed the capacity of Trypanosoma cruzi epimastigotes to transform into metacyclic forms (Macias et al., 1999). Melatonin was also shown to increase RBC invasion by Plasmodium chabaudi, and to affect the maturation of the parasite (Hotta et al., 2000). Effects on parasite maturation were also seen with P. falciparum (Beraldo and Garcia, 2005), although no effects of melatonin were found for P. berghei and P. yoelli, which typically develop asynchronously (Bagnaresi et al., 2009). Furthermore, studies in mice that make low or undetectable levels of melatonin also showed a normal parasite development cycle in RBCs (Hirako et al., 2018; Kennaway, 2019). Thus, even if melatonin plays a role in Plasmodium rhythms, it is not necessary and other synchronizers must be involved. As for Leishmania, footpad lesions in hamsters following $L$. amazonensis infection were larger when the animals were treated with a melatonin receptor antagonist, and reduced after melatonin treatment (Laranjeira-Silva et al., 2015).

\section{Feeding and Metabolism}

The feeding rhythms of the host can also constitute a timing cue for parasites, as was shown for $P$. chabaudi infection. Two recent studies showed that the parasite stage rhythms in RBCs had a different phase when infected mice were fed during the day or at night (Hirako et al., 2018; Prior et al., 2018). Since the glucose rhythm was shifted in day vs. night-fed mice, it was suggested that it might mediate the effect on the parasites (Prior et al., 2018). Cytokines seem to be involved in this glucose regulation during infection, and rhythms in parasite developmental stages were abolished in IFN $\gamma$ KO mice, in TNF $\alpha$ receptor mice, and in mice lacking IFN $\gamma$ receptor in hematopoietic cells (Hirako et al., 2018). Similar results were found in chemically-induced diabetic mice, which have constant high glucose blood levels (Hirako et al., 2018). TNF $\alpha$ involvement is reminiscent of the dynamic relationship between rising blood TNF $\alpha$ levels preceding body temperature increases in patients infected with P. vivax (Karunaweera et al., 1992). 


\section{THE IMPACT OF IMMUNE RHYTHMS ON THE RESPONSE TO PARASITIC INFECTIONS}

All cells of the immune system express clock genes, and immune cells such as macrophages and $\mathrm{T}$ cells have $4-8 \%$ of their transcriptome under circadian regulation (Keller et al., 2009; Nobis et al., 2019). Accordingly, a role was found for circadian clocks in regulating various immune responses, including during infection (Nobis et al., 2018). For example, various functions of macrophages and monocytes, including phagocytosis, secretion of cytokines and trafficking between tissues, are clock-controlled (Labrecque and Cermakian, 2015; Nobis et al., 2018). A rhythm was found in the expression of many of the pattern recognition receptors (PRRs), as well as in key signaling molecules downstream of these receptors, involved in responses to pathogen-associated molecular patterns (PAMPs) (Nobis et al., 2018; Silver et al., 2018). Rhythms in chemokines and their receptors can also lead to the time-dependent recruitment of immune cells to an infection site. Therefore, both the numbers of immune cells and their responsiveness to signals can vary according to the time of day. Given the interplay between parasites and immune cells (in particular those serving as hosts for the parasites) (Gazzinelli et al., 2014; Atayde et al., 2016), an influence of the immune rhythms on the progression of parasitic disease is likely. Such a circadian influence was indeed uncovered in a few recent studies.

The infection of mice by Leishmania parasites during late day led to larger lesions than upon infection in the late night (Laranjeira-Silva et al., 2015), and this is likely due to circadian regulation because similar rhythms were seen in $L$. major-infected mice kept in constant darkness (Kiessling et al., 2017). Interestingly, late day/early night infection led to a stronger recruitment of innate immune cells such as neutrophils and macrophages, which serve as host cells for Leishmania. The rhythms in parasite load, immune cell recruitment and chemokine expression were abolished in mice lacking a circadian clock specifically in cells of hematopoietic origin, demonstrating a role of immune cell clocks in regulating Leishmania infection (Kiessling et al., 2017).

A circadian regulation was also seen in the case of infection with the helminth Trichuris muris. While the Leishmania study looked at the immediate inflammatory response, the time of Trichuris infection led to a difference in the timing of worm expulsion and antibody production a few weeks later (Hopwood et al., 2018). Knocking out clock function specifically in dendritic cells led to a loss of the time-dependency (Hopwood et al., 2018).

\section{EVIDENCE FOR CIRCADIAN TIMING MECHANISMS WITHIN PARASITES}

Another layer of complexity is the possibility that the parasites themselves might have their own endogenous clock (Table 1). This is likely, given that various single-cell eukaryotes display endogenous circadian rhythms [e.g., green alga Ostreococcus tauri (Pfeuty et al., 2012), dinoflagellate Lingulodinium polyedra (Hastings, 2007), fungus Neurospora crassa (Dunlap et al., 2007)].
Recently, a study showed endogenous circadian rhythms of gene expression in Trypanosoma brucei (Rijo-Ferreira et al., 2017). Isolated parasites were synchronized using temperature cycles and RNA sequencing was performed to identify transcripts varying with a $24 \mathrm{~h}$ period. About $15 \%$ of all transcripts were found to be rhythmic. The rhythms were temperature compensated, a defining feature of circadian clocks. Pathway analysis showed that many of the oscillating transcripts were involved in metabolic functions. Interestingly, the sensitivity of the parasite to oxidative stress and its resistance to the drug suramin were both under circadian control, underscoring the biological significance of parasite-borne rhythms (Rijo-Ferreira et al., 2017).

A recent report has addressed a similar question in Plasmodium (Subudhi et al., 2019). Mice infected with $P$. chabaudi (which displays a $24 \mathrm{~h}$ development cycle in RBCs) were housed under a light-dark cycle, and blood sampled over $30 \mathrm{~h}$ was used for RNA sequencing: over 5,000 P. chabaudi transcripts displayed $\sim 24 \mathrm{~h}$ rhythms. However, since these rhythms could be driven by host signals, published transcriptomic data from in vitro-cultured $P$. falciparum were reanalyzed for $\sim 24 \mathrm{~h}$ period variation. The $P$. falciparum development cycle period is $48 \mathrm{~h}$, allowing transcripts dependent on this cycle to be distinguished from circadian transcripts. A significant $24 \mathrm{~h}$ component was found for $\sim 500$ transcripts. Among these, 110 genes were also among the rhythmic $P$. chabaudi genes, suggesting they were endogenously generated in $P$. chabaudi as well.

Although the identification of endogenous timing mechanisms in protozoan parasites is in its infancy and presents some challenges, the situation can be different for other groups of parasites. Indeed, research on fungal parasites might benefit from the detailed knowledge about the molecular clock of the fungus Neurospora crassa. For example, a study on the plant pathogen Botrytis cinerea described the existence of genes homologous to clock components White Collar Complex and Frequency (FRQ) of N. crassa (Hevia et al., 2015; Larrondo and Canessa, 2019). These B. cinerea clock genes function in an analogous way, with a core feedback loop where FRQ negatively feeds back on its own expression.

As for helminths, it is likely that like other animals they have a molecular clock machinery. Although helminths are not a monophyletic group, knowledge about clock mechanisms in the nematode Caenorhabditis elegans [for which circadian research is beginning (Goya et al., 2016; Olmedo et al., 2017)] might be of help.

\section{MISALIGNMENT OF HOST-PARASITE RHYTHMS}

Many parasites display circadian or daily rhythms on their own, either generated by endogenous clocks or conferred by a rhythmically active vector. A consequence is that the alignment of these parasite rhythms with those of the vertebrate host might be beneficial for either the parasite or the host, and conversely, that the misalignment of the host and parasite rhythms might impact 
the host-parasite relationship. A few studies have directly tackled this question.

The Reece group has taken advantage of the $24 \mathrm{~h}$ rhythms in the intra-RBC development cycle of $P$. chabaudi to determine the impact of a mismatch between rhythms in the host and parasites. Infected $\mathrm{RBCs}$ were used to infect recipient mice which were either on the same light-dark cycle as the donor mice, or an inverted light-dark cycle. A mismatch between parasite and host rhythms led to reduced parasite density and gametocyte production (O'Donnell et al., 2011), confirming that host-parasite rhythm alignment aids the parasite. A followup study showed that this mismatch effect does not depend on either the developmental stage of the parasite used for infection or on the route of infection, and has an impact at early infection stages (O'Donnell et al., 2013). A misalignment of the P. chabaudi and host rhythms also impacted rhythmic parasite genes, and led to a reduced development cycle period (Subudhi et al., 2019).

The existence of a circadian clock in the fungus $B$. cinerea (see above) has allowed researchers to investigate the interplay between the clocks in the pathogen and in the infected plant (Larrondo and Canessa, 2019). The outcome of the infection of Arabidopsis thaliana by B. cinerea depends on the time of day at which it occurs (larger infected area at dusk; Hevia et al., 2015). Experiments using clock gene mutants of either B. cinerea or A. thaliana showed that the clock in the fungus is necessary for this time-dependency. Moreover, in experiments where the two organisms' clocks were entrained on out-of-phase light-dark cycles, dusk fungus always induced larger lesions, independent of the plants phase (even though it had previously been shown that plants have more efficient defenses against necrotrophic fungi in the morning; Hevia et al., 2015).

\section{EFFECT OF PARASITES ON THE HOST'S CIRCADIAN RHYTHMS}

\section{Effects on Behavioral Rhythms}

Many examples of parasites affecting the host's daily behavior are known (Table 1). In particular, parasites can manipulate an intermediate host to optimize transmission to the final (vertebrate) host, thus completing their life cycle (Lefevre et al., 2009; de Bekker et al., 2014). Here we review some examples where host's behavior manipulation has a daily component.

Snails Potamopyrgus antipodarum are the intermediate hosts for the trematode parasitic worm Microphallus. Snails carrying the infective forms of the parasite were found on the top of rocks in the morning, at a time where the ducks (final hosts for the parasite) are feeding, but later in the morning and for the rest of the day, were underside the rocks to escape predation by fish (not final hosts for Microphallus; Levri and Lively, 1996). This is consistent with manipulation of P. antipodarum by the parasite, although it could rather be that increased hunger of the snails extends their foraging duration. Another trematode using a snail as an intermediate host, Schistosoma mansoni, shows a daily rhythm of emergence of the larval stage that transfers to the final mammalian host. Interestingly, emergence occurs in the daytime for parasites infecting humans (diurnal) and in the evening for parasites infecting rats (nocturnal) (Mouahid et al., 2012).

The case of insect-manipulating fungi is also interesting. One striking example is the manipulation of ants (Camponotus leonardi) by parasitic fungus Ophiocordyceps unilateralis. Infected ants abandon their normal activities and climb to the top of plants before biting leaves and dying (de Bekker et al., 2014). This favors the dissemination of the parasite's spores. Interestingly, this behavioral manipulation is highly synchronized, with "zombie" ants exhibiting the biting behavior around midday (Hughes et al., 2011). Recent transcriptomic analysis of $O$. unilateralis has uncovered many rhythmic transcripts in the fungi, including putative clock components, which could be involved in the daily regulation of the infection and host manipulation (de Bekker et al., 2017).

\section{Effects on Circadian Clocks}

Human African trypanosomiasis (sleeping sickness) is a parasitic disease that perfectly illustrates the capacity of parasites to modulate host's rhythms. Trypanosomiasis is caused by the protozoan parasite Trypanosoma brucei, transmitted by tsetse fly's bite. Despite the common name of the disease (which comes from the coma observed in patients where the parasite has invaded the brain), infected patients do not show hypersomnia, but a disorganization of their sleep-wake cycles, becoming worse as the disease progresses (Buguet et al., 1993). An advance of the melatonin rhythm was also observed, but no change in core body temperature rhythm (Claustrat et al., 1998). In T. brucei-infected rats, however, both a phase shift of the temperature rhythm and changes in sleep profile were observed (Grassi-Zucconi et al., 1995; Seke Etet et al., 2012). Interestingly, some of the phenotypes were present even before parasites start accumulating in the brain, although they became more prominent after that stage (Seke Etet et al., 2012). Disorganized sleep-wake cycles and a phase advance of rhythms controlled by the SCN central clock begs the question of whether the infection causes changes of circadian clocks themselves. A number of studies have addressed the effects of T. brucei infection on SCN function. In infected rats, a reduced firing rate of $\mathrm{SCN}$ neuron and a phase-advance of their activity rhythms was observed (Lundkvist et al., 1998), as well as disrupted synaptic activity (Lundkvist et al., 2002), and an altered Fos expression profile (Bentivoglio et al., 1994). Moreover, infection led to a reduced expression of glutamate receptors, which mediate light response, and consistently, to a reduced response of the clock to light (Peng et al., 1994).

An in-depth analysis of $T$. brucei's ability to disrupt host rhythms was recently published (Rijo-Ferreira et al., 2018). $T$. brucei-infected mice showed increased daytime activity and a shifted temperature rhythm under a light-dark cycle, and a shorter free-running period. Further analysis revealed that an advance of the endogenous rhythms seemed to underlie the daytime activity. Interestingly, the short period phenotype was observable before the occurrence of the parasite in the brain, suggesting an indirect effect via a peripheral factor. Tissues of infected (and control) PER2::Luciferase mice were put in culture, 
showing a shortened period and a phase advance of the rhythms in some peripheral tissues, including adipose tissue, an organ with high parasitemia. Such effects were blunted upon suramin treatment. Similar effects were also found in tissues infected in vitro, excluding the involvement of systemic cues, for example due to inflammation (Rijo-Ferreira et al., 2018). The in vitro data is consistent with a prior report of a shortened period in the pituitary, but not the SCN, of infected animals (Lundkvist et al., 2010) after short term infection (in the Rijo-Ferreira study, an effect on the SCN was seen only after long-term infection).

The multimammate mouse, Mastomys natalensis, was used as a rodent model susceptible to both the human parasite $T$. brucei gambiense and T. brucei brucei, a pathogen not infectious to humans. Interestingly, infection with T. b. gambiense, but not with T. b. brucei, led to a $30 \%$ decrease in SCN neuronal density, while astrocyte activation was noted for both (Tesoriero et al., 2018). This, together with the phase shift of melatonin rhythm in human patients (Claustrat et al., 1998), suggests that the effects on host's circadian clocks also exist in human patients.

Despite all these reports on T. brucei, very little is known on the effect of other parasites on host clock mechanisms. Trypanosoma cruzi-infected mice showed a lower amplitude of locomotor activity rhythms, attenuated light responses and slower entrainment to a new LD cycle (Fernandez Alfonso et al., 2003). Mice infected with Plasmodium chabaudi displayed reduced locomotor activity and body temperature at night, in a parasite genotype-specific way (Prior et al., 2019). Such effects might be due to the inflammation occurring in the host, as various immune mediators were shown to affect circadian rhythms (Cermakian et al., 2014). This is supported by the work of Rijo-Ferreira et al.: in parallel to T. brucei, they tested behavioral and bioluminescence rhythms in mice infected with P. chabaudi. A suppression of activity levels and clock gene expression in adipose tissue was found, both likely acute effects of systemic inflammation, as no effects were seen on the period of rhythms in cultured tissues (Rijo-Ferreira et al., 2018).

Knowledge of the effect of Leishmania infection on host clocks is even scarcer: the only study that has addressed this question showed that L. amazonensis does not alter melatonin levels or rhythms in hamsters up to 21 days post infection (LaranjeiraSilva et al., 2015). A manipulation of clock mechanisms may also occur in fish: in a transcriptomic analysis of Nile tilapia infected with Saprolegna parasite vs. non infected controls, one of the most prominent category of modified genes was that of clock genes and regulators (Ellison et al., 2018).

\section{REFERENCES}

Atayde, V. D., Hassani, K., da Silva Lira Filho, A., Borges, A. R., Adhikari, A., Martel, C., et al. (2016). Leishmania exosomes and other virulence factors: impact on innate immune response and macrophage functions. Cell. Immunol. 309, 7-18. doi: 10.1016/j.cellimm.2016.07.013

Bagnaresi, P., Alves, E., Borges da Silva, H., Epiphanio, S., Mota, M. M., and Garcia, C. R. (2009). Unlike the synchronous Plasmodium falciparum and P. chabaudi infection, the $P$. berghei and $P$. yoelii asynchronous infections are not affected by melatonin. Int. J. Gen. Med. 2, 47-55. doi: 10.2147/IJGM.S3699

\section{CONCLUDING REMARKS}

There are now many examples of the importance of circadian or daily rhythms in host-parasite interactions. So far, data has been mostly descriptive, and future research will need to address in particular: (1) how host circadian clocks and rhythms impact the initiation and outcome of parasitic infections; (2) the mechanisms involved in the effects of the parasites on host behavior and cellular functions; (3) the parasite-intrinsic rhythms and the clock mechanisms that underlie them.

Daily rhythms can represent an adaptative mechanism used by parasites to favor their transmission, e.g., to become available to be taken up by an intermediate vector or by the final vertebrate host. They can also enhance parasite survival by aligning parasite activity with the rhythmic metabolism, immunity, and behavior of the host, as well as environmental cycles in abiotic environments. Therefore, a better knowledge of the mechanisms underlying the circadian regulation of host-parasite interactions may allow the design of new strategies to prevent and control parasitic infections. It will also be beneficial to extend this research beyond more common parasites such as Plasmodium and T. brucei, to neglected tropical diseases such as filariasis, which are known to have a clear time-of-day regulation and affect hundreds of million people worldwide.

\section{AUTHOR CONTRIBUTIONS}

PC, MO, and NC wrote the paper.

\section{FUNDING}

Research in the Cermakian lab was supported by grants from the Natural Sciences and Engineering Research Council of Canada (NSERC), the Canadian Institutes of Health Research (CIHR), McGill Faculty of Medicine and McGill initiative in Computational Medicine. Research in the Olivier lab was supported by grants from NSERC and CIHR. PC was supported by a fellowship from McGill Faculty of Medicine.

\section{ACKNOWLEDGMENTS}

The authors thank Dr. David Morse for critical review of the manuscript and members of Cermakian laboratory for discussions.

Bass, J. (2012). Circadian topology of metabolism. Nature 491, 348-356. doi: $10.1038 /$ nature11704

Bentivoglio, M., Grassi-Zucconi, G., Peng, Z. C., Bassetti, A., Edlund, C., and Kristensson, K. (1994). Trypanosomes cause dysregulation of c-fos expression in the rat suprachiasmatic nucleus. Neuroreport 5, 712-714. doi: 10.1097/00001756-199402000-00013

Beraldo, F. H., and Garcia, C. R. (2005). Products of tryptophan catabolism induce $\mathrm{Ca} 2+$ release and modulate the cell cycle of Plasmodium falciparum malaria parasites. J. Pineal Res. 39, 224-230. doi: 10.1111/j.1600-079X.2005.0 0249.x 
Buguet, A., Bert, J., Tapie, P., Tabaraud, F., Doua, F., Lonsdorfer, J., et al. (1993). Sleep-wake cycle in human African trypanosomiasis. J. Clin. Neurophysiol. 10, 190-196. doi: 10.1097/00004691-199304000-00006

Cermakian, N., Westfall, S., and Kiessling, S. (2014). Circadian clocks and inflammation: reciprocal regulation and shared mediators. Arch. Immunol. Ther. Exp. 62, 303-318. doi: 10.1007/s00005-014-0286-x

Claustrat, B., Buguet, A., Geoffriau, M., Bogui, P., Mouanga, G., Stanghellini, A., et al. (1998). Plasma melatonin rhythm is maintained in human African trypanosomiasis. Neuroendocrinology 68, 64-70. doi: 10.1159/000054351

de Bekker, C., Merrow, M., and Hughes, D. P. (2014). From behavior to mechanisms: an integrative approach to the manipulation by a parasitic fungus (Ophiocordyceps unilateralis s.l.) of its host ants (Camponotus spp.). Integr. Comp. Biol. 54, 166-176. doi: 10.1093/icb/icu063

de Bekker, C., Will, I., Hughes, D. P., Brachmann, A., and Merrow, M. (2017). Daily rhythms and enrichment patterns in the transcriptome of the behaviormanipulating parasite Ophiocordyceps kimflemingiae. PLoS ONE 12:e187170. doi: 10.1371/journal.pone.0187170

Di Cesare, A., Otranto, D., Di Giulio, E., Simonato, G., Latrofa, M. S., La Torre, F., et al. (2013). Microfilarial periodicity of Dirofilaria repens in naturally infested dogs. Parasitol. Res. 112, 4273-4279. doi: 10.1007/s00436-013-3619-5

Doehring, E., Vester, U., Ehrich, J. H., and Feldmeier, H. (1985). Circadian variation of ova excretion, proteinuria, hematuria, and leukocyturia in urinary schistosomiasis. Kidney Int. 27, 667-671. doi: 10.1038/ki.1985.62

Duguay, D., and Cermakian, N. (2009). The crosstalk between physiology and circadian clock proteins. Chronobiol. Int. 26, 1479-1513. doi: 10.3109/07420520903497575

Duke, B. O., Scheffel, P. D., Guyon, J., and Moore, P. J. (1967). The concentration of Onchocerca volvulus microfilariae in skin snips taken over twenty-four hours. Ann. Trop. Med. Parasitol. 61, 206-219. doi: 10.1080/00034983.1967.11686480

Dunlap, J. C., Loros, J. J., Colot, H. V., Mehra, A., Belden, W. J., Shi, M., et al. (2007). A circadian clock in Neurospora: how genes and proteins cooperate to produce a sustained, entrainable, and compensated biological oscillator with a period of about a day. Cold Spring Harb. Symp. Quant. Biol. 72, 57-68. doi: 10.1101/sqb.2007.72.072

Ellison, A. R., Uren Webster, T. M., Rey, O., Garcia de Leaniz, C., Consuegra, S., Orozco-terWengel, P., et al. (2018). Transcriptomic response to parasite infection in Nile tilapia (Oreochromis niloticus) depends on rearing density. BMC Genomics 19:723. doi: 10.1186/s12864-018-5098-7

Fernandez Alfonso, T., Celentano, A. M., Gonzalez Cappa, S. M., and Golombek, D. A. (2003). The circadian system of Trypanosoma cruzi-infected mice. Chronobiol. Int. 20, 49-64. doi: 10.1081/CBI-120017687

Gazzinelli, R. T., Kalantari, P., Fitzgerald, K. A., and Golenbock, D. T. (2014). Innate sensing of malaria parasites. Nat. Rev. Immunol. 14, 744-757. doi: $10.1038 /$ nri3742

Goya, M. E., Romanowski, A., Caldart, C. S., Benard, C. Y., and Golombek, D. A. (2016). Circadian rhythms identified in Caenorhabditis elegans by in vivo longterm monitoring of a bioluminescent reporter. Proc. Natl. Acad. Sci. U.S.A. 113, E7837-E7845. doi: 10.1073/pnas.1605769113

Grassi-Zucconi, G., Harris, J. A., Mohammed, A. H., Ambrosini, M. V., Kristensson, K., and Bentivoglio, M. (1995). Sleep fragmentation, and changes in locomotor activity and body temperature in trypanosome-infected rats. Brain Res. Bull. 37, 123-129. doi: 10.1016/0361-9230(94)00265-3

Hastings, J. W. (2007). The Gonyaulax clock at 50: translational control of circadian expression. Cold Spring Harb. Symp. Quant. Biol. 72, 141-144. doi: 10.1101/sqb.2007.72.026

Hawking, F. (1967). The 24-hour periodicity of microfilariae: biological mechanisms responsible for its production and control. Proc R Soc. Lond. Ser. B Biol. Sci. 169, 59-76. doi: 10.1098/rspb.1967.0079

Hawking, F. (1970). The clock of the malaria parasite. Sci. Am. 222, 123-131. doi: 10.1038/scientificamerican0670-123

Hawking, F., Jennings, T., Louis, F. J., and Tuira, E. (1981). The mechanisms which affect the periodic cycle of Pacific Wuchereria bancrofti microfilariae. J. Helminthol. 55, 95-100. doi: 10.1017/S0022149X00025554

Hawking, F., Moore, P., Gammage, K., and Worms, M. J. (1967). Periodicity of microfilariae. XII. the effect of variations in host body temperature on the cycle of loa loa, monnigofilaria setariosa, Dirofilria immitis and other filariae. Trans. R Soc. Trop. Med. Hyg. 61, 674-683. doi: 10.1016/0035-9203(67) 90132-0
Hawking, F., Worms, M. J., and Gammage, K. (1968). Host temperature and control of 24-hour and 48-hour cycles in malaria parasites. Lancet 1, 506-509. doi: 10.1016/S0140-6736(68)91469-4

Hevia, M. A., Canessa, P., Muller-Esparza, H., and Larrondo, L. F. (2015). A circadian oscillator in the fungus Botrytis cinerea regulates virulence when infecting Arabidopsis thaliana. Proc. Natl. Acad. Sci. U.S.A. 112, 8744-8749. doi: 10.1073/pnas. 1508432112

Hirako, I. C., Assis, P. A., Hojo-Souza, N. S., Reed, G., Nakaya, H., Golenbock, D. T., et al. (2018). Daily rhythms of TNF $\alpha$ expression and food intake regulate synchrony of plasmodium stages with the host circadian cycle. Cell Host Microbe. 23, 796-808 e796. doi: 10.1016/j.chom.2018.04.016

Hopwood, T. W., Hall, S., Begley, N., Forman, R., Brown, S., Vonslow, R., et al. (2018). The circadian regulator BMALl programmes responses to parasitic worm infection via a dendritic cell clock. Sci. Rep. 8:3782. doi: 10.1038/s41598-018-22021-5

Hotta, C. T., Gazarini, M. L., Beraldo, F. H., Varotti, F. P., Lopes, C., Markus, R. P., et al. (2000). Calcium-dependent modulation by melatonin of the circadian rhythm in malarial parasites. Nat. Cell Biol. 2, 466-468. doi: 10.1038/35017112

Hughes, D. P., Andersen, S. B., Hywel-Jones, N. L., Himaman, W., Billen, J., and Boomsma, J. J. (2011). Behavioral mechanisms and morphological symptoms of zombie ants dying from fungal infection. BMC Ecol. 11:13. doi: 10.1186/1472-6785-11-13

Karunaweera, N. D., Grau, G. E., Gamage, P., Carter, R., and Mendis, K. N. (1992). Dynamics of fever and serum levels of tumor necrosis factor are closely associated during clinical paroxysms in Plasmodium vivax malaria. Proc. Natl. Acad. Sci. U.S.A. 89, 3200-3203. doi: 10.1073/pnas.89.8.3200

Keller, M., Mazuch, J., Abraham, U., Eom, G. D., Herzog, E. D., Volk, H. D., et al. (2009). A circadian clock in macrophages controls inflammatory immune responses. Proc. Natl. Acad. Sci. U.S A. 106, 21407-21412. doi: 10.1073/pnas.0906361106

Kennaway, D. J. (2019). Melatonin research in mice: a review. Chronobiol. Int. 36, 1167-1183. doi: 10.1080/07420528.2019.1624373

Kiessling, S., Dubeau-Laramee, G., Ohm, H., Labrecque, N., Olivier, M., and Cermakian, N. (2017). The circadian clock in immune cells controls the magnitude of Leishmania parasite infection. Sci. Rep. 7:10892. doi: 10.1038/s41598-017-11297-8

Labrecque, N., and Cermakian, N. (2015). Circadian clocks in the immune system. J. Biol. Rhythms 30, 277-290. doi: 10.1177/0748730415577723

Laranjeira-Silva, M. F., Zampieri, R. A., Muxel, S. M., Floeter-Winter, L. M., and Markus, R. P. (2015). Melatonin attenuates Leishmania (L.) amazonensis infection by modulating arginine metabolism. J. Pineal Res. 59, 478-487. doi: 10.1111/jpi.12279

Larrondo, L. F., and Canessa, P. (2019). The clock keeps on ticking: emerging roles for circadian regulation in the control of fungal physiology and pathogenesis. Curr. Top. Microbiol. Immunol. 422, 121-156. doi: 10.1007/82_2018_143

Lefevre, T., Lebarbenchon, C., Gauthier-Clerc, M., Misse, D., Poulin, R., and Thomas, F. (2009). The ecological significance of manipulative parasites. Trends Ecol. Evol. 24, 41-48. doi: 10.1016/j.tree.2008. 08.007

Levri, E. P., and Lively, C. M. (1996). The effects of size, reproductive condition, and parasitism on foraging behaviour in a freshwater snail, Potamopyrgus antipodarum. Anim. Behav. 51, 891-901. doi: 10.1006/anbe.1996.0093

Lundkvist, G. B., Christenson, J., ElTayeb, R. A., Peng, Z. C., Grillner, P., Mhlanga, J., et al. (1998). Altered neuronal activity rhythm and glutamate receptor expression in the suprachiasmatic nuclei of Trypanosoma brucei-infected rats. J. Neuropathol. Exp. Neurol. 57, 21-29. doi: 10.1097/00005072-199801000-00004

Lundkvist, G. B., Hill, R. H., and Kristensson, K. (2002). Disruption of circadian rhythms in synaptic activity of the suprachiasmatic nuclei by African trypanosomes and cytokines. Neurobiol. Dis. 11, 20-27. doi: $10.1006 /$ nbdi.2002.0536

Lundkvist, G. B., Sellix, M. T., Nygard, M., Davis, E., Straume, M., Kristensson, K., et al. (2010). Clock gene expression during chronic inflammation induced by infection with Trypanosoma brucei brucei in rats. J. Biol. Rhythms 25, 92-102. doi: 10.1177/0748730409360963

Macias, M., Rodriguez-Cabezas, M. N., Reiter, R. J., Osuna, A., and AcunaCastroviejo, D. (1999). Presence and effects of melatonin in Trypanosoma cruzi. J. Pineal Res. 27, 86-94. doi: 10.1111/j.1600-079X.1999.tb00601.x 
Martinez-Bakker, M., and Helm, B. (2015). The influence of biological rhythms on host-parasite interactions. Trends Ecol. Evol. 30, 314-326. doi: 10.1016/j.tree.2015.03.012

Meireles-Filho, A. C., and Kyriacou, C. P. (2013). Circadian rhythms in insect disease vectors. Mem. Inst. Oswaldo Cruz. 108 (Suppl. 1), 48-58. doi: 10.1590/0074-0276130438

Mouahid, G., Idris, M. A., Verneau, O., Theron, A., Shaban, M. M., and Mone, H. (2012). A new chronotype of Schistosoma mansoni: adaptive significance. Trop. Med. Int. Health 17, 727-732. doi: 10.1111/j.1365-3156.2012.02988.x

Nobis, C. C., Dubeau Laramee, G., Kervezee, L., Maurice De Sousa, D., Labrecque, N., and Cermakian, N. (2019). The circadian clock of CD8 T cells modulates their early response to vaccination and the rhythmicity of related signaling pathways. Proc. Natl. Acad. Sci. U.S.A. 116, 20077-20086. doi: 10.1073/pnas.1905080116

Nobis, C. C., Labrecque, N., and Cermakian, N. (2018). From immune homeostasis to inflammation, a question of rhythms. Curr. Opin. Physiol. 5, 90-98. doi: 10.1016/j.cophys.2018.09.001

O’Donnell, A. J., Mideo, N., and Reece, S. E. (2013). Disrupting rhythms in Plasmodium chabaudi: costs accrue quickly and independently of how infections are initiated. Malar. J. 12:372. doi: 10.1186/1475-2875-12-372

O’Donnell, A. J., Schneider, P., McWatters, H. G., and Reece, S. E. (2011). Fitness costs of disrupting circadian rhythms in malaria parasites. Proc. Biol. Sci. 278, 2429-2436. doi: 10.1098/rspb.2010.2457

Olmedo, M., Merrow, M., and Geibel, M. (2017). Sleeping Beauty? Developmental timing, sleep, and the circadian clock in caenorhabditis elegans. Adv. Genet. 97, 43-80. doi: 10.1016/bs.adgen.2017.05.001

Otranto, D., Dantas-Torres, F., Giannelli, A., Abramo, F., Ignjatovic Cupina, A., Petric, D., et al. (2013). Cutaneous distribution and circadian rhythm of Onchocerca lupi microfilariae in dogs. PLoS Negl. Trop. Dis. 7:e2585. doi: 10.1371/journal.pntd.0002585

Peng, Z. C., Kristensson, K., and Bentivoglio, M. (1994). Dysregulation of photic induction of Fos-related protein in the biological clock during experimental trypanosomiasis. Neurosci. Lett. 182, 104-106. doi: 10.1016/0304-3940(94)90217-8

Pfeuty, B., Thommen, Q., Corellou, F., Djouani-Tahri el, B., Bouget, F. Y., and Lefranc, M. (2012). Circadian clocks in changing weather and seasons: lessons from the picoalga Ostreococcus tauri. Bioessays 34, 781-790. doi: 10.1002/bies.201200012

Prior, K. F., O’Donnell, A. J., Rund, S. S. C., Savill, N. J., van der Veen, D. R., and Reece, S. E. (2019). Host circadian rhythms are disrupted during malaria infection in parasite genotype-specific manners. Sci. Rep. 9:10905. doi: 10.1038/s41598-019-47191-8

Prior, K. F., van der Veen, D. R., O’Donnell, A. J., Cumnock, K., Schneider, D., Pain, A., et al. (2018). Timing of host feeding drives rhythms in parasite replication. PLoS Pathog. 14:e1006900. doi: 10.1371/journal.ppat.1006900

Reece, S. E., Prior, K. F., and Mideo, N. (2017). The life and times of parasites: rhythms in strategies for within-host survival and between-host transmission. J. Biol. Rhythms 32, 516-533. doi: 10.1177/0748730417718904
Rijo-Ferreira, F., Carvalho, T., Afonso, C., Sanches-Vaz, M., Costa, R. M., Figueiredo, L. M., et al. (2018). Sleeping sickness is a circadian disorder. Nat. Commun. 9:62. doi: 10.1038/s41467-017-02484-2

Rijo-Ferreira, F., Pinto-Neves, D., Barbosa-Morais, N. L., Takahashi, J. S., and Figueiredo, L. M. (2017). Trypanosoma brucei metabolism is under circadian control. Nat. Microbiol. 2, 17032. doi: 10.1038/nmicrobiol.2017.32

Rund, S. S., O'Donnell, A. J., Gentile, J. E., and Reece, S. E. (2016). Daily rhythms in mosquitoes and their consequences for malaria transmission. Insects 7:E14. doi: 10.3390/insects7020014

Saran, R., Sharma, M. C., Gupta, A. K., Sinha, S. P., and Kar, S. K. (1997). Diurnal periodicity of Leishmania amastigotes in peripheral blood of Indian Kala-azar patients. Acta Trop. 68, 357-360. doi: 10.1016/S0001-706X(97)00104-6

Schneider, P., Rund, S. S. C., Smith, N. L., Prior, K. F., O’Donnell, A. J., and Reece, S. E. (2018). Adaptive periodicity in the infectivity of malaria gametocytes to mosquitoes. Proc. Biol. Sci. 285:20181876. doi: 10.1098/rspb.2018.1876

Seke Etet, P. F., Palomba, M., Colavito, V., Grassi-Zucconi, G., Bentivoglio, M., and Bertini, G. (2012). Sleep and rhythm changes at the time of Trypanosoma brucei invasion of the brain parenchyma in the rat. Chronobiol. Int. 29, 469-481. doi: 10.3109/07420528.2012.660713

Silver, A. C., Buckley, S. M., Hughes, M. E., Hastings, A. K., Nitabach, M. N., and Fikrig, E. (2018). Daily oscillations in expression and responsiveness of toll-like receptors in splenic immune cells. Heliyon 4:e00579. doi: 10.1016/j.heliyon.2018.e00579

Subudhi, A. K., O’Donnell, A. J., Ramaprasad, A., Abkallo, H. M., Kaushik, A., Ansari, H. R., et al. (2019). Disruption of the coordination between host circadian rhythms and malaria parasite development alters the duration of the intraerythrocytic cycle. BioRxiv. doi: 10.1101/791046

Takahashi, J. S. (2017). Transcriptional architecture of the mammalian circadian clock. Nat. Rev. Genet. 18, 164-179. doi: 10.1038/nrg.2016.150

Tesoriero, C., Xu, Y. Z., Mumba Ngoyi, D., and Bentivoglio, M. (2018). Neural damage in experimental Trypanosoma brucei gambiense infection: the suprachiasmatic nucleus. Front. Neuroanat. 12:6. doi: $10.3389 /$ fnana.2018.00006

Westwood, M. L., O’Donnell, A. J., de Bekker, C., Lively, C. M., Zuk, M., and Reece, S. E. (2019). The evolutionary ecology of circadian rhythms in infection. Nat. Ecol. Evol. 3, 552-560. doi: 10.1038/s41559-019-0831-4

Conflict of Interest: The authors declare that the research was conducted in the absence of any commercial or financial relationships that could be construed as a potential conflict of interest.

Copyright (C) 2019 Carvalho Cabral, Olivier and Cermakian. This is an open-access article distributed under the terms of the Creative Commons Attribution License (CC $B Y)$. The use, distribution or reproduction in other forums is permitted, provided the original author(s) and the copyright owner(s) are credited and that the original publication in this journal is cited, in accordance with accepted academic practice. No use, distribution or reproduction is permitted which does not comply with these terms. 